\title{
The changing National Health Service: market-based reform and morality

\author{
Comment on "Morality and Markets in the NHS"
}

\section{Lucy Frith ${ }^{*}$}

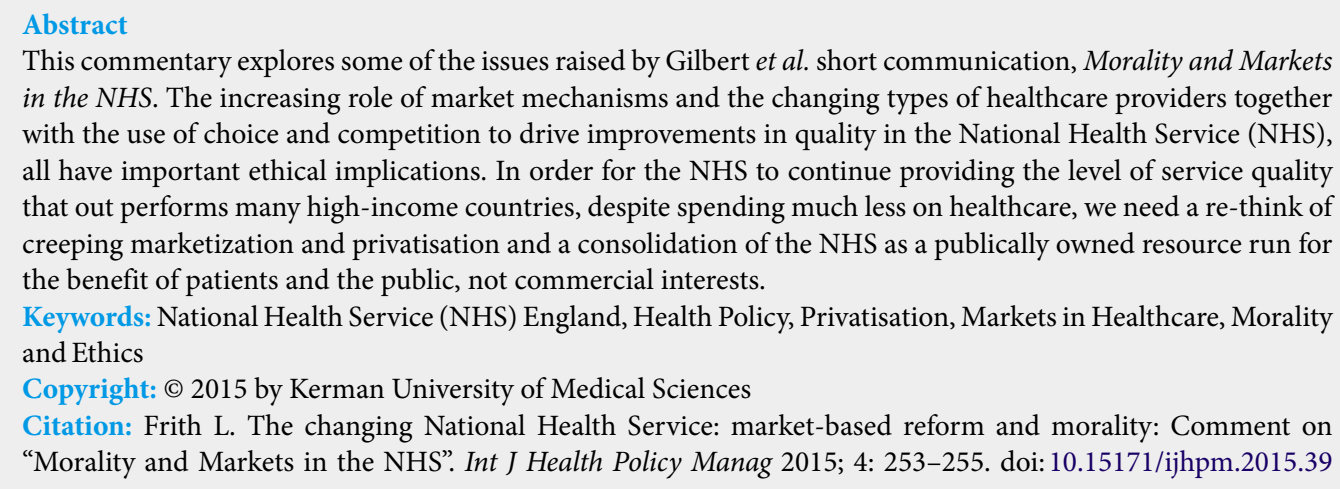

This commentary explores some of the issues raised by Gilbert et al. short communication, Morality and Markets in the NHS. The increasing role of market mechanisms and the changing types of healthcare providers together with the use of choice and competition to drive improvements in quality in the National Health Service (NHS), all have important ethical implications. In order for the NHS to continue providing the level of service quality that out performs many high-income countries, despite spending much less on healthcare, we need a re-think of creeping marketization and privatisation and a consolidation of the NHS as a publically owned resource run for the benefit of patients and the public, not commercial interests.

Keywords: National Health Service (NHS) England, Health Policy, Privatisation, Markets in Healthcare, Morality and Ethics

Copyright: @ 2015 by Kerman University of Medical Sciences

Citation: Frith L. The changing National Health Service: market-based reform and morality: Comment on "Morality and Markets in the NHS". Int J Health Policy Manag 2015; 4: 253-255. doi: 10.15171/ijhpm.2015.39

\section{Article History:}

Received: 3 February 2015 Accepted: 21 February 2015 ePublished: 24 February 2015

*Correspondence to: Lucy Frith Email: 1.j.frith@liverpool.ac.uk
$\mathrm{T}$ he article by Gilbert et al. (1), considering the marketbased reform of the National Health Service (NHS), is timely as the funding and organisation of the NHS was a key issue in the May 2015 general election in the United Kingdom (UK). What kind of health service the public want and what kind of organisations (private, social enterprises or existing NHS contractors) should provide care, are key questions that all the political parties have to address.

Gilbert et al. (1) give an overview of the history of the NHS and argue that, 'The post-2000 era has been defined by a radical shift in the philosophy of healthcare policy-makers'. (p1) and this has resulted in a turn toward market ideology in health policy. The reasons they give for this 'turn' are changes in: the structure of the economy in the UK; attitudes of patients and an increase in patient autonomy; changing demographics, with an increasingly elderly population; and a rise in chronic conditions. It is hard to attribute causes to complex social phenomena, but I would argue that the commitment to a free market ideology that has characterised British governments since 1979 is one of the key drivers for change in the NHS. Hence, there has been continuity in healthcare policy from Thatcher's first government in 1979, culminating in the 2012 Health and Social Care Act. The current changes in the NHS are the product of a gradual movement towards the privatisation and marketisation of the NHS.

The justifications for this creation of a more competitive market in healthcare have been set out in policy documents spanning 30 years and can be summarised as $(2,3)$ : a belief that the private sector is better managed; market forces will encourage leaner more efficient service provision and help contain costs; competition and patient choice will drive quality and innovation; and a decentralised health service will be more responsive to local needs and encourage citizen participation.

The culmination of these policies was the passage of the Health and Social Care Act in 2012. There are twin forces at play here: an increased use of market forces (defined as creating a competitive environment where services and labour are commodified) and privatisation (defined as ownership of public assets sold or transferred to the private sector) (4). The central aim of this legislation was to extend market forces into the NHS to a much greater degree than before. The Act changed how healthcare is commissioned (bought) by creating a national NHS Commissioning Board, now called NHS England. NHS England oversees clinical commissioning groups and these have responsibility for commissioning services for their local populations replacing Primary Care Trusts and Strategic Health Authorities. The aim of these consortiums is to give more local control and be more sensitive to market mechanisms. The Act has accelerated moves to encourage other organisations outside the NHS to bid for services previously offered by the NHS. The 'any qualified provider' initiative, (5) will enable patients to choose from a range of providers from different sectors: commercial, third sector and the NHS. The central aim of this diversification is to increase patient choice and stimulate competition between these different providers.

The 2012 Act also abolished the Secretary of State for Health's duty to provide comprehensive health services throughout England and Wales, replacing it with a duty to exercise other functions to secure provision. This is an often misunderstood, 
but key part, of the 2012 Act that will have profound implications for all aspects of the NHS.

"The effect was to transform the English NHS from a nationally-mandated public service required of the government under primary legislation, into a service based on commercial contracting, underpinned by ministerial and local discretion and secondary legislation, and exacerbated by non-accountability to Parliament of commissioners and providers. Abolition of the duty of the Secretary of State to provide or secure provision of health services was the seminal change that brought this transformation about" (6).

As Hunter (7) notes, the Coalition government's neoliberalism drives these health reforms, the aim is to roll back the state and increasingly rely on the use of private providers. Hinchingbrooke hospital in Cambridgeshire serves as an example of some of the problems with this approach. In November 2011 it was taken over by a private company Circle Health. Not long into the contract reports suggested that Circle was facing finance problems and had not been able to make the cost savings anticipated (8). Such companies have other obligations, to ensure that their services are translated into profits and this, arguably, can create a conflict of interest for such organisations that could threaten patient care. This concern was realised at Hinchingbrooke when it was rated as 'inadequate' in 2014 by the Care Quality Commission (CQC) (who inspect health and social care to ensure appropriate stands) and the hospital was put on 'special measures': 'The inspection highlighted serious concerns and CQC has told the trust it must improve' (9). In January 2015 Circle Holdings announced that it would end the contract to run the hospital, citing problems with funding cuts and increased demand for accident and emergency services. While all these pressures are recognised, unlike publically owned hospitals, private companies have the option to walk away from these difficult situations [under the terms of the 10 year contract, it could be ended once they had invested a specific amount of money ( $£ 5$ million), a form of 'get out' clause (although reports suggest it has to date spent slightly less than this figure - $£ 4.84 \mathrm{~m}$ )] (10). When healthcare provision is owned and run by the NHS these fluctuations can be weathered and continuity in organisation and patient care maintained.

Gilbert et al. (1) give two solutions to the actual and future problems with an increase in the marketization of the NHS. First, they put forward a values-explicit approach that uses values as a means of regulating market forces, values that should be made explicit and consistent throughout the NHS (p3). Second, a systems-based approached should be utilised that looks holistically at the healthcare system, which will foster a collaborative rather than competitive environment (p4). In regard to the first suggestion it could be argued that this is already in operation with the NHS Constitution.

Lord Darzi's review of the NHS in 2008 recommended that the NHS should make explicit its values and commitments to patients and this should be enshrined in a constitution: 'establish[ing] the principles and values of the NHS in England. [The Constitution] sets out rights to which patients, public and staff are entitled, and pledges which the NHS is committed to achieve, together with responsibilities which the public, patients and staff owe to one another to ensure that the NHS operates fairly and effectively' (11). The context for this is summed by this statement from the NHS Institute for Innovation and Improvement: 'As our healthcare system becomes increasingly devolved, autonomous and entrepreneurial, there is a need for system-wide values, which reaffirm the social purpose of the NHS, to staff, patients and the public and inspire behaviours that put the needs of patients, staff and the public foremost in people's minds' (12). The Health Act 2009 stipulated that all bodies providing NHS services (NHS, private and third sector providers) must 'have regard' to the Constitution in all their actions and decisions. The NHS Constitution was recently updated in 2013 and it has been given a high prominence in all NHS documentation. This is part of a drive to make organisations and patients more aware of the Constitution so that it can have more influence on practice (13).

Despite these moves it can be asked, how useful is the Constitution in practice? How is compliance with the Constitution to be policed? Who ensures that the increasingly diverse range of healthcare providers will adhere to these values? The Constitution includes pledges (non-legally binding 'goals') that independent organisations should have regard to, for example that all employees should have rewarding jobs. The 2012 Health Act includes a provision that Clinical Commissioning Groups must promote the Constitution and they will be held to account by the NHS England. However, in practice what does 'have regard' to the Constitution actually mean and what measures constitute promoting it? The Constitution can only be applied within the existing context and how much influence this can have on the basic structure of the NHS and how it can meaningfully ensure ethical practice is debatable.

Gilbert et al.'s (1) second suggestion is to embrace a systems theory approach to the NHS. One part of this is to encourage integration of services and provide more 'joined up' care. This is something that all healthcare systems struggle with and it is likely that an increasingly fragmented health service with different providers and types of organisation will decrease the likelihood of effective integration (14). Their suggestion that the Principles and Rules for Cooperation and Competition could, 'strike a balance between the benefits of co-operation and competition.' (p5) does not get to the heart of the problem to my mind. First, these regulations have been superseded by sections 75-7 of the Health and Social Care Act (15) and second, it is not clear what limits will be placed on competition as an end in itself. As the British Medical Association (BMA) note: 'Despite Government assurances, many, including the BMA, felt the Regulations were unclear as to when commissioners would be able to legitimately restrict competition' (16). This lack of clarity in the regulations and the government's commitment to a competitively run health service mean that it will be hard to restrict competition even on grounds of ensuring cooperation and continuity of good quality care. This drive for free market competition, or what passes for this in a healthcare system, (17) will have detrimental effects for attempts to integrate services. The BMA again note: 'It was also not clear from the regulations alone whether commissioners would be able to prioritise integration over competition and choice without leaving themselves open to challenge from Monitor...[And 
this is] potentially damaging to the comprehensiveness and integration of services' (18). Therefore, the legal regulatory framework of the 2012 Act needs to be re-thought before greater integration and co-operation can be realised.

The increasing role of the market in healthcare provision and the use of choice and competition to drive improvements in quality all have important ethical implications (19). The changes made by the 2012 Act were heavily criticised, the BMA for example said: 'Since the Act received Royal Assent in 2012, we have maintained our opposition to increased competition and the development of the market in the NHS' (18). There is a campaign for a NHS Reinstatement Bill (20) that wants to abolish competition, the provider-purchaser split, re-establish public bodies and accountability and restrict the role of commercial companies in the NHS. These kinds of reforms are a good place to start rethinking the last 30 years of health policy. In order for the NHS to continue to provide the level of service quality that out performs many high income countries, despite spending much less on healthcare (21), we need a re-think of creeping marketization and privatisation and aim to consolidate the NHS as a publically owned resource run for the benefit of patients and the public, not commercial interests.

\section{Ethical issues}

Not applicable.

\section{Competing interests}

Author declares that she has no competing interests.

\section{Author's contribution}

$L F$ is the single author of the manuscript.

References

1. Gilbert B, Clarke E, Leaver E. Morality and Markets in the NHS. Int J Health Policy Manag 2014; 3: 371-6. doi: 10.15171/ ijhpm.2014.123

2. Dopson S. Changing forms of managerialism in the NHS: hierarchies, markets and networks. In: Gabe J, Calnan M (eds). The new sociology of the health service. London: Routledge; 2009 .

3. Mohan J. Visions of privatization: new labour and the reconstruction of the NHS. In: Gabe J, Calnan M (eds). The new sociology of the health service. London: Routledge; 2009.

4. Whitfield D. A typology of privatisation and marketization. European Services Strategy Unit. 2006. Available from: http:// www.european-services-strategy.org.uk/publications/essuresearch-reports/essu-research-paper-1/essu-research-paper-1-2. pdf

5. NHS Confederation. Any qualified provider. Discussion paper, Issue 10, July 2011. Available from: http://www.nhsconfed. org/ /media/Confederation/Files/Publications/Documents/Any_ qualified_provider.pdf

6. Pollock A, Price D. Duty to care: In defence of universal health care. Policy Paper. Centre for Labour and Social Studies. 2013. [cited 28th January 2015]. http://classonline.org.uk/ docs/2013_05_Policy_Paper_-_A_duty_to_care_\%28Allyson_ Pollock_David_Price\%29.pdf

7. Hunter D. A response to Rudolf Klein: a battle may have been won but perhaps not the war. J Health Polit Policy Law 2013; 38: 871-7. doi: 10.1215/03616878-2210512

8. Hawkes N. Why are the media so soft on Circle? BMJ 2012; 345: e5351. doi: 10.1136/bmj.e5351

9. Care Quality Commission (CQC). Chief Inspector of Hospitals recommends Hinchingbrooke Health Care NHS Trust is placed in special measures following Care Quality Commission inspection. 9 January, 2015. [cited 28th January 2015]. Available from: http:// www.cqc.org.uk/content/chief-inspector-hospitals-recommendshinchingbrooke-health-care-nhs-trust-placed-special

10. The Guardian. Circle in talks to exist private contract to run Hinchenbrooke Hosptial. 9th January 2015. Available from: http://www.theguardian.com/society/2015/jan/09/circle-exitprivate-contract-hinchingbrooke-nhs

11. Department of Health. NHS Constitution. London: DH; 2009.

12. Institute for Innovation and Improvement. Living our Local Values. NHS; 2008.

13. National Health Service (NHS). Report on the Effect of the NHS Constitution. London: Department of Health; 2012.

14. Improving the allocation of health resources in England: How to decide who gets what. Kings Fund. 2013. Available from: http://www.kingsfund.org.uk/sites/files/kf/field/field_publication file/improving-the-allocation-of-health-resources-in-englandkingsfund-apr13.pdf

15. Monitor. Procurement, patient choice and competition regulations: guidance. 2013. Available from: https://www.gov. uk/government/publications/procurement-patient-choice-andcompetition-regulations-guidance

16. BMA Competition Law and the NHS. 2015. Available from: http://bma.org.uk/working-for-change/doctors-in-the-nhs/ reconfiguration-and-integration-new/competition-and-choicenew/choice-and-competition/section-75-briefing

17. Donaldson C. Credit Crunch Healthcare. Bristol: Polity Press; 2011.

18. BMA Lords debate on motion to annul Section 75 regulations. 24 April 2013. Available from: http://bma.org.uk/working-forchange/doctors-in-the-nhs/reconfiguration-and-integration-new/ competition-and-choice-new/choice-and-competition/section75-briefing

19. Frith L. The NHS and Market Forces in Health Care: The need for organisational ethics. J Med Ethics 2013; 39; 17-21. doi: 10.1136/medethics-2012-100713

20. NHS Reinstatement Bill. Available from: http://www.nhsbill2015. org

21. Ingleby $D$, McKee M, Mladovsky $P$, Rechel $B$. How the NHS measures up to other health systems. BMJ 2012; 344: e1079. doi: $10.1136 /$ bmj.e1079 